\title{
RANDOMIZED CLINICAL TRIAL COMPARING TWO DIFFERENT TECHNIQUES OF LOCAL ANESTHESIA (SUBCUTANEOUS VERSUS SUBCUTANEOUS \& DEEP INFILTRATION) FOR POSTOPERATIVE PAIN IN PATIENTS UNDERGOING OPEN APPENDECECTOMY
}

By

AHMED I.REFAAT ${ }^{1}$, MOHAMMED S. HEDAYA ${ }^{2}$, HUSSEIN M. EZZAT ${ }^{2}$, M.MAHER H.FAYED ${ }^{1}$, A.F. SALAMA ${ }^{2}$ and AHMED H. HELMY ${ }^{2}$

Departments of Anesthesiology ${ }^{1}$ and Surgery ${ }^{2}$, Theodore Bilharz Research Institute, Imbaba P.O. Box 30, Giza, Egypt

\begin{abstract}
This study compared the postoperative analgesic effect of local anesthetic (LA) injected subcutaneous (SC) alone versus local anesthetic injected both SC and deep in patients undergoing open appendecectomy operations. Sixty patients ASA class I- II undergoing open appendecectomy for presumed acute appendicitis will be randomly assigned into three groups. After routine monitoring, anesthesia induction was performed with propofol, fentanyl and, cis-atracurium; later, maintenance was continued with isoflurane. GA received local infiltration of the skin prior to incision with bupivacaine $0.25 \%$ $(10 \mathrm{ml}), \mathrm{GB}$ received received half the bupivacaine infiltrated into the skin and other half deep-to external oblique prior to incision to create a local nerve field blockade \& GC received half dose of saline subcutaneous \& half deep to external oblique muscle prior to incision. Postoperative pain was assessed using visual analogue score (VAS) at 1, 4, 8, \& 24 hours post extubation. Pethidine $1 \mathrm{mg} / \mathrm{kg}$ was given if VAS is $\geq 4$.

All patients in GA (SC) and Control required postoperative analgesics, compared to only $60 \%$ of the patients in $\mathrm{GB}$ (SC+deep). Time for the first analgesic requirement was prolonged in GB compared to other groups $(\mathrm{P}<0.01)$. VAS scores were significantly lower in patients of GB in the first $8 \mathrm{hr}$. postoperative compared to GA \& GC $(\mathrm{P}<0.01)$.

Key Words: Appendectomy, pre-incisional infiltration, bupivacaine.
\end{abstract}

\section{Introduction}

Open appendectomy is one of the most frequently performed surgical procedures in the worldwide population and is a cause of significant pain and discomfort in the postoperative period (Jensen et al, 2004). Inadequate postoperative pain control may lead to cardiovascular and respiratory complications, prolonged hospitalization and increase health cost (Shang and Gan, 2003). The efficient analgesic regimen should provide safe, effective analgesia, with limited side effects (Jensen et al, 2004).

Multimodal approaches to the provision of postoperative analgesia include central neuron blocked (opioids), non-steroid anti-inflammatory drugs, and use of local anesthetics (Fischer and Simanski, 2005). Local anesthetic agent can be applied by using many methods, such as spinal blocks, epidural blocks, periphral nerve blocks and preincisional infiltration (Halaszynski, 2009). The wound infiltration analgesia has become an important part of multimodal analgesia (Andersen et al, 2007) to decrease the postoperative pain, improve patient satisfaction, reduce opioid consumption and fasten patient recovery. The use of local anesthetics instead of opioid minimizes opioid side effects postoperative nausea and vomiting (PONV), reduces nursing work, decreases resting pain, enhance early intake of oral fluids and food, and thus reduce patient hospitalization (Vallejo et al, 2006).

The surgical incision activate inflammatory, hormonal and immune responses (Giannoudis et al, 2006) to administer local anesthetics into wound before the incision (pre-emptive analgesia) was done to reduce postoperative pain by 
blocking the nociceptive afferent pain pathways of peripheral and central nervous system (Cantore et al, 2008). Direct infiltration of the surgical area with local anesthetics was an easier, relatively inexpensive, technically simple and safe for local analgesia (Kerr et al, 2008).

Postoperative outcome of the infiltrative treatment is affected by several factors; as the surgery type, infiltration administration time, location, concentration and volume of local anesthetics, adjuvant medications and measurement methods (Otte et al, 2008).

The analgesic effect derived from the local anesthetic was due to the constituent drug direct actions as blockage of iongated $\mathrm{Na}$ channels on A-delta and C-type nerves and therefore nociceptive nerve endings (Hollmann et al, 2000).

However, the beneficial effect in terms of pain scores and mobility of the local infiltration analgesia exceeded the expected action duration of the local anesthetic itself; as the local anesthetic drugs might be the reason (Swanton and Shorten, 2003).

The local anesthetics anti-inflammatory effect might be due to several factors including decrease the release of inflammatory mediators from neutrophils reduce formation of oxygen free radicals, decrease neutrophil adhesion to the endothelium and decrease edema formation (Cassuto et al, 2006).

Almost all LAs can be effectively used for wound infiltration, but long acting and less toxic LAs are preferred to provide postoperative pain relief (Zinc et al, 2008). Lidocaine is one of the amide local anesthetic that has a rapid onset of action and an intermediate duration of efficacy. It also can be used as antiarrhythmic, analgesic and anti-inflammatory drug. Its most side effects as an anesthetic drug are related to administration technique and result in central nervous system excitation and cardiovascular toxicity (Yardeni et al, 2009). Bupivacaine with its long lasting effect is most commonly injected into surgical wound sites for the relief of postoperative pain (Lohsiriwat et al, 2004; Edwards et $a l, 2011)$. Exposure to excessive quantities result into systemic toxicity in the form of central nervous system excitation and cardiovascular effects, including hypotension, bradycardia, arrhythmias, and/or cardiac arrest (Roberge et al, 1998). Levobupivacaine is an S-isomer of racemic bupivacaine that has emerged as a safer alternative for regional anesthesia. It has recently been introduced as a promising long-acting local anesthetic with a lower toxicity than bupivacaine (Crina et $a l, 2008)$. Ropivacaine was likely chosen for its reduced cardiotoxicity in comparison to bupivacaine as well as for its intrinsic vasoconstrictor properties (Gutton et al, 2013). Thus, bupivacaine has been superceded by levobupivacaine or ropivacaine, both of which have less ability to produce cardiovascular depression and seizure activity because of overdose or intravascular injection, especially in neonates, children, or pregnant women (Ozmen et al, 2011; Gutton et al, 2013).

In this study, $0.25 \%$ bupivacaine was used as the local anesthetic for wound infiltration to provide post-operative pain relief. It is most commonly injected into surgical wound sites with longer half-life than lidocaine, and can potentially provide relief of postoperative pain for up to 20 hours after the surgery.

\section{Material and Method:}

This study was conducted after approval of the institutional ethical committee and obtaining an informed written consent from every patient. The study involved sixty adult patients aged 25-65 years of either sexes ASA class I \& $\Pi$ undergoing open appendectomy for acute appendicitis. They were randomly assigned into three groups. GA received local infiltration of the skin prior to incision with bupivacaine $0.25 \%(10 \mathrm{ml})$. GB received half the bupivacaine infiltrated into the skin and the other half deep-to the external oblique prior to skin incision to create 
a local nerve field blockade. GC (control group) received $10 \mathrm{ml}$ of saline, $5 \mathrm{ml}$ infiltrated into the skin and other $5 \mathrm{ml}$ deep-to external oblique prior to skin incision.

All patients were monitored using routine monitoring including: 5 lead ECG, non-invasive blood pressure monitoring, pulse oximtrey, capnography, and anesthetic gas analyzer. All patients received standard general anesthesia with propofol $2 \mathrm{mg} / \mathrm{kg}$, cis-atracurium $0.15 \mathrm{mg} / \mathrm{kg}$ \& fentanyl $2 \mathrm{ug} / \mathrm{kg}$. Anesthesia was maintained with isoflurane $1 \%+30 \%$ oxygen in air \& controlled mechanical ventilation to maintain ends tidal $\mathrm{CO} 2$ between 35 $40 \mathrm{mmHg}$. Muscle relaxation was maintained by cis-atracurium by the rate 0.02 $\mathrm{mg} / \mathrm{kg}$.

In post anesthesia care unit (PACU), postoperative pain was assessed using visual analogue score (VAS) on a 0 to 10 scale where a score of 0 represents no pain and 10 is the worst pain imaginable. VAS was measured at $1,4,8, \& 24 \mathrm{~h}$ post extubation. Whenever the VAS score $\geq 4$ or the patient requested pain medication, analgesia was provided by pethidine $1 \mathrm{mg} / \mathrm{kg}$ intramuscular. Number of patients required analgesia and the time to first analgesic requirement were recorded.

Statistical analysis: Data were expressed as $\mathrm{M} \pm \mathrm{S}$ deviation (SD). Comparison between the mean values of the two groups was done using Mann-Whitney U test while comparison relative to the baseline in the same group were performed using Friedman's ANOVA with post hoc Wilcoxon matched pairs test. $\mathrm{P}=$ less than 0.05 was significant.

\section{Results}

Among the 60 patients, there were no significant differences between groups in demographic variable (Tab. 1). All in GA and $\mathrm{GC}$ required postoperative analgesics, while in GB (SC+ deep), only 40\% didn't require analgesia postoperatively. Time for the first analgesic requirement was prolonged in GB compared to GA \& GC (Tab. 2). VAS scores were significantly lower in GB in the first eight hr. postoperative compared to GA \& GC, without great difference in value at eight hr. postoperative between all groups. The VAS was lowered again in GB at $24 \mathrm{hr}$. postoperative compared to GA \& GC (Fig. 1).

Table 1: Demographic features of studied group.

\begin{tabular}{|l|c|c|c|}
\hline & GA $(\mathrm{n}=20)$ & GB $(\mathrm{n}=20)$ & GC $(\mathrm{n}=20)$ \\
\hline Age (yrs.) & $22.8 \pm 4.5$ & $23.8 \pm 6.36$ & $23.75 \pm 4.29$ \\
\hline Sex (F/M) & $17 / 3(85 \% / 15 \%)$ & $18 / 2(90 \% / 10 \%)$ & $17 / 3(85 \% / 15 \%)$ \\
\hline BMI & $27.5 \pm 2.19$ & $27.65 \pm 2.70$ & $27.25 \pm 2.79$ \\
\hline ASA class $(1)$ & $17 / 3(85 \% / 15 \%)$ & $18 / 2(90 \% / 10 \%)$ & $17 / 3(85 \% / 15 \%)$ \\
\hline
\end{tabular}

$\mathrm{GA}=$ subcutaneous group $\mathrm{GB}=$ subcutaneous + deep group $\mathrm{GC}=$ control group

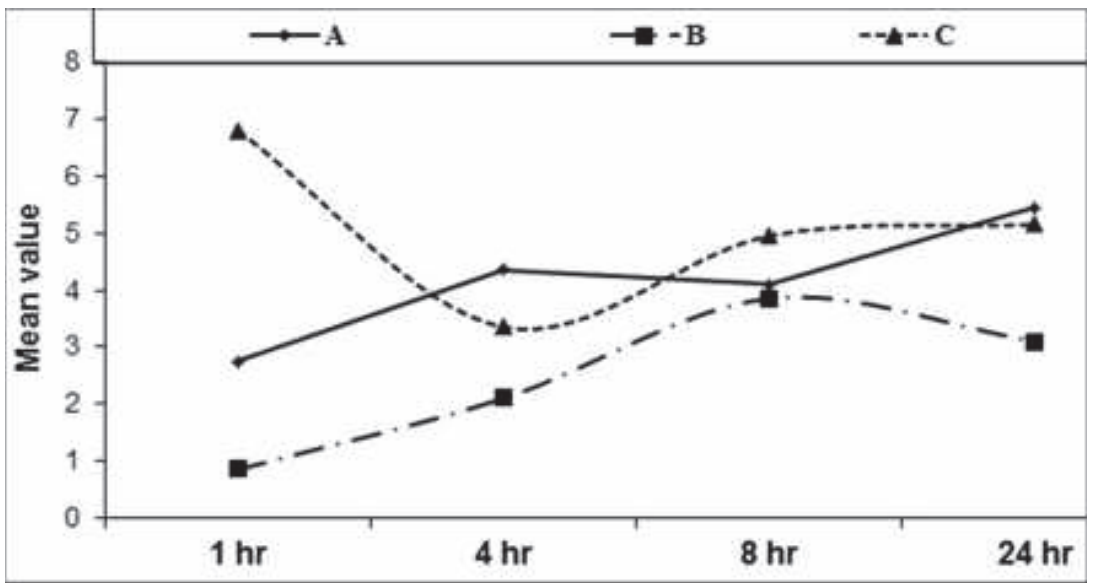

Fig 1: Mean VAS measured after different duration time of surgery among groups. ${ }^{\mathrm{a}} \mathrm{p}<0.01$ relative $\mathrm{GC},{ }^{\mathrm{b}} \mathrm{p}<0.01$ relative $\mathrm{SC}$ GA 
Table 2: Postoperative Pethidine requirements in groups.

\begin{tabular}{|l|c|c|c|}
\hline & GA $(n=20)$ & GB $(n=20)$ & GC $(n=20)$ \\
\hline Patients didn't require postoperative analgesia & $0(0 \%)$ & $8(40 \%)$ & $0(0 \%)$ \\
\hline $1 \mathrm{hr}$ & $4(20 \%)$ & $0(0 \%)$ & $18(90 \%)$ \\
\hline $4 \mathrm{hr}$ & $11(55 \%)$ & $1(5 \%)$ & $1(5 \%)$ \\
\hline $8 \mathrm{hr}$ & $5(25 \%)$ & $10(50 \%)$ & $1(5 \%)$ \\
\hline $24 \mathrm{hr}$ & $0(0 \%)$ & $1(5 \%)$ & $0(0 \%)$ \\
\hline \multicolumn{2}{|r|}{$\mathrm{P}<0.01$}
\end{tabular}

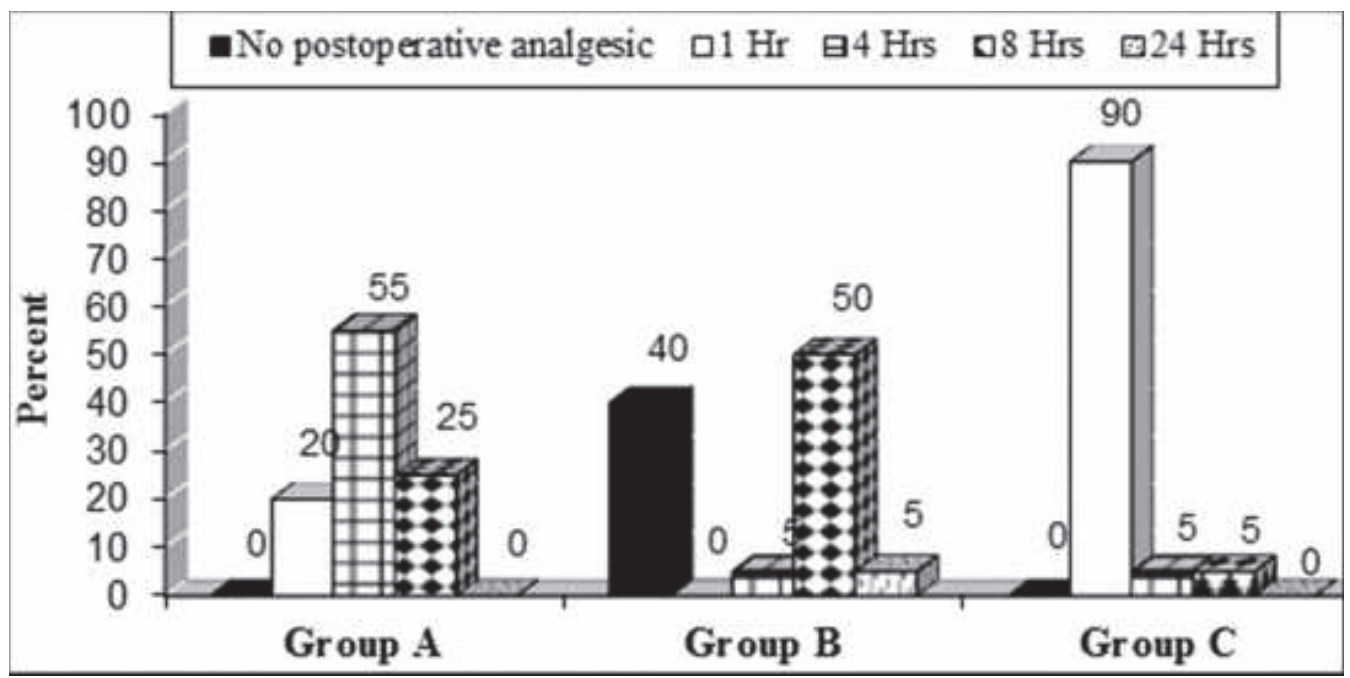

Fig 2: Statistical comparison of groups comparing postoperative pethidine requirement at 1, 4, $8 \& 24 \mathrm{hr}$. and patients who didn't require analgesia

Discussion

This study revealed that injection of local anesthetic both SC and deep infiltration in patients undergoing open appendicectomy opertations reduced postoperative pain score, analgesic requirements and the number of patients required analgesia together with prolonged postoperative analgesic duration compared to $\mathrm{SC}$ injection of local anesthetic and control group.

The results agreed with many trials about the efficacy of pre-emptive anesthetic infiltration. Cherian et al. (1997) used $0.375 \%$ bupivacaine infiltrated to the muscle and subcutaneous tissue before closure of the incision line in unilateral laminectomy patients due to lumbar disc hernia. Postoperative elapsed time for the requirement of the first analgesics was $807.7 \& 181.4$ minutes in the bupivacaine-infiltrated and controls respectively and concluded that this method was effective and safe. Bagul et al. (2005) infiltrated the subcutaneous tissues with $10 \mathrm{ml}$ of $0.5 \%$ bupivacaine pre- incisional in thyroidectomy patients, and found that pain scores were lower in bupivacaine-infiltrated compared to controls, at the first six hr., but without any difference at the $24^{\text {th }} \mathrm{hr}$. Morphine was not needed in the bupivacaine group, but it was $25 \%$ in the controls. They concluded that bupivacaine-infiltration was easy and gave good pain control on thyroidectomy patients, without any unfavorable effect on wound healing. Also, Cervini et al. (2002) used $0.5 \%$ bupivacaine and reported the benefit of preemptive bupivacaine infiltration that resulted in a decreased need for postoperative parenteral narcotics.

On the contrary, Ko et al. (1997) used a combination of lidocaine hydrochloride and bupivacaine hydrochloride and found no benefits in reducing postoperative pain and analgesic requirements or in shortening hospital stay length. This might be due to the differences in technique of anesthetics infiltration as not included the abdominal muscular layer, but only the subcutaneous tissue. 
Similar results in terms of consumption of opioids were reported (Cobby et al, 1997; Johansson et al, 2000; Klein et al, 2000; Updike et al, 2003) as VAS scores and time for additional analgesics between groups administered local anesthetics to the superficial or deep layers of abdomen and controls. However, with local anesthetics injected to all abdominal layers, the requirement of postoperative opioids decreased.

In pediatric appendectomy Edwards et al. (2011) reported that $0.25 \%$ bupivacaine administration gave no additional benefit over regular simple analgesia, but this might be due to the fact the wound infiltration technique did not include the abdominal muscle layer, but used neurovascular plane and subcutaneous tissue prior to skin closure. Others (Cherian et al, 1997; Cervini et al, 2002; Bagul et al, 2005 ) used $0.5 \%$ bupivacaine and recommended the higher concentrations $(0.375 \%$ to $0.5 \%)$ than the smaller one $0.25 \%$ used in this study.

\section{Conclusion}

The injection $0.25 \%$ bupivacaine both SC and deep infiltration in patients undergoing open appendicectomy opertations provided less postoperative pain score, analgesic requirements and number of patients required analgesia and prolonged analgesic duration together with better patient's satisfaction score when compared to only SC injection of local anesthetic group and the control group.

\section{References}

Andersen, K, Pfeiffer-Jensen, M, Haraldsted V, 2007: Reduced hospital stay and narcotic consumption, and improved mobilization with local and intraarticular infiltration after hip arthroplasty: a randomized clinical trial of an intraarticular technique versus epidural infusion in 80 patients. Acta Orthop. 78:180-6.

Bagul, A, Taha, R, Metcalfe, M, Brook, N, Nicholson, M, 2005: Pre-incision infiltration of local anesthetic reduces postoperative pain with no effects on bruising and wound cosmesis after thyroid surgery. Thyroid 15:12458.
Cantore, F, Boni, L, Di Giuseppe, M, Giavarini, L, Rovera, F, et al, 2008: Pre-incision local infiltration with levobupivacaine reduces pain and analgesic consumption after laparoscopic cholecystectomy: a new device for day-case procedure. Int. J. Surg. 6, 1:S8992.

Cassuto, J, Sinclair, R, Bonderovic, M, 2006: Anti-inflammatory properties of local anesthetics and their present and potential clinical implications. Acta Anesthesiol. Scandinavia 50, 3:265-82.

Cervini, P, Smith, L, Urbach, D, 2002: The effect of intraoperative bupivacaine administration on parenteral narcotic use after laparoscopic appendectomy. Surg. Endosc. 16: 1579-82.

Cherian, M, Mathews, M, Chandy, M, 1997: Local wound infiltration with bupivacaine in lumbar laminectomy. Surg. Neurol. 47:120-2.

Cobby, T, Reid, M, 1997: Wound infiltration with local anesthetic after abdominal hysterectomy. Br. J. Anesth. 78:431-2.

Crina, L, Donal, B, Buggy, J, 2008: Update on local anesthetics: focus on levobupivacaine. Ther. Clin. Risk Manag. 4, 2:381-92.

Edwards, T, Carty, SA, Carr, A, Lambert, A, 2011: Local anesthetic wound infiltration following paediatric appendicectomy: a randomised controlled trial: Time to stop using local anaesthetic wound infiltration following paediatric appendicectomy? Int. J. Surg. 9: 314-7.

Fischer, H, Simanski, C, 2005: A procedure-specific systematic review and consensus recommendations for analgesia after total hip replacement. Anesthesia 60, 12:1189-202.

Giannoudis, P, Dinopoulos, H, Chalidis, B, Hall, G, 2006: Surgical stress response. Injury $37,5:$ S3-9.

Gutton, C, Bellefleur, J, Puppo, S, Brunet, J, Antonini, F, et al, 2013: Lidocaine versus ropivacaine for perineal infiltration postepisiotomy. Int. J. Gyn. Obst. 122:33-6.

Halaszynski, T, 2009: Pain management in the elderly and cognitively impaired patient: the role of regional anesthesia and analgesia. Curr. Opin. Anesthesiol. 22, 5:594-9.

Hollmann, M, Durieux, M, 2000: Local anesthetics and the inflammatory response: A new therapeutic indication? Anesthesiol. 93, 3:858-75.

Jensen, S, Andersen, M, Nielsen, J, Qvist, $\mathbf{N}$, 2004: Incisional local anesthesia versus 
placebo for pain relief after appendectomy in children: A double- blinded controlled randomised trial. Eur. J. Pediatr. Surg. 14:410-3. Johansson, A, Axelson, J, Ingvar, C, Luttropp, H, Lundberg, J, 2000: Preoperative ropivacaine infiltration in breast surgery. Acta Anesthesiol. Scandinavia 44:1093-8.

Kerr, D, Kohan, L, 2008: Local infiltration analgesia: A technique for control of acute postoperative pain following knee and hip surgery: A case study of 325 patients. Acta Orthopaed. 79, 2:174-83.

Klein, J, Heaton, J, Thompson, J, Cotton, B, Davidson, A, et al, 2000: Infiltration of the abdominal wall with local anesthetic after total abdominal hysterectomy has no opioidsparing effect. Br. J. Anesth. 84:248-9.

Ko, C, Thompson, J, Alcantara, A, Hiyama, D, 1997: Preemptive analgesia in patients undergoing appendectomy. Arch. Surg. 132:874-7.

Lohsiriwat, V, Lert-akyamanee, N, Rushatamukayanunt, W, 2004: Efficacy of preincisional bupivacaine infiltration on postoperative pain relief after appendectomy: prospective double-blind randomized trial. Wld. J. Surg. 28:947-50.

Otte, K, Husted, H, Andersen, L, Kristensen, B, Kehlet, H, 2008: Local infiltration analgesia in total knee arthroplasty and hip resurfacing: A methodological study. Acute Pain 10, 3/4:111-6.

Ozmen, S, Ozmen, O, Kasapoglu, F, 2011: Effects of levobupivacaine versus bupivacaine infiltration on postoperative analgesia in pediatric tonsillectomy patients: a random- ized, double-blind, placebo-controlled study. Ann. Otol. Rhinol. Laryngol. 120:489-93.

Parpaglioni, R, Baldassini, B, Barbati, G, Celleno, D, 2009: Adding sufentanil to levobupivacaine or ropivacaine intrathecal anaesthesia affects the minimum local anaesthetic dose required. Acta Anesthesiol. Scandinavia 53:1214-20.

Roberge, C, McEwen, M, 1998: The effects of local anesthetics on postoperative pain. AORN J. 68:1003-12.

Shang, A, Gan, T, 2003: Optimizing postoperative pain management in ambulatory patient. Drugs 63: 855-67.

Swanton, B, Shorten, G, 2003: Anti-inflammatory effects of local anesthetic agents. Int. Anesthesiol. Clin. 41, 1:1-19.

Updike, G, Manolitsas, T, Cohn, D, Eaton, L, Fowler, J, et al, 2003: Pre-emptive analgesia in gynecologic surgical procedures: Preoperative wound infiltration with ropivacaine in patients who undergo laparotomy through a midline vertical incision. Am. J. Obst. Gyn. 188:901-5.

Vallejo, M, Phelps, A, Sah, N, Romeo, R, Falk, J, et al, 2006: Preemptive analgesia with bupivacaine for segmental mastectomy. Reg. Anesth. Pain Med. 31:227-32.

Yardeni, I, Beilin, B, Mayburd, E, et al, 2009: The effect of perioperative intravenous lidocaine on postoperative pain and immune function. Anesth. Analg. 109:1464-9.

Zink, W, Graf, B, 2008: Toxicity of local anesthetics: The place of ropivacaine and levobupivacaine. Curr. Opin. Anaesthesiol. 21: 645-50. 